\title{
Treatment of knee osteoarthritis with a new formulation of a fixed-dose combination of glucosamine sulfate and bovine chondroitin: a multicenter, randomized, single-blind, non-inferiority clinical trial
}

\author{
Andrea Barranjard Vannucci Lomonte ${ }^{1 *}$ (D), Emerson Gimenez ${ }^{2}$, Antônio Carlos da Silva ${ }^{3}$, \\ Sebastião Cezar Radominski ${ }^{4}$, Morton Aaron Scheinberg ${ }^{5}$, Antônio Carlos Ximenes ${ }^{6}$ and \\ Cristiano Augusto de Freitas Zerbini ${ }^{1}$
}

\begin{abstract}
Objectives: To compare the efficacy and safety of a new formulation of a fixed dose combination of glucosamine sulfate (GS; $1500 \mathrm{mg}$ ) and bovine chondroitin sulfate (CS; $1200 \mathrm{mg}$ ) versus the reference product (RP) in patients with knee osteoarthritis (OA).

Methods: In this multicenter, randomized, single-blind trial, 627 patients with knee osteoarthritis (OA)—KellgrenLawrence grades 2 or 3 and mean score $\geq 40 \mathrm{~mm}$ in the WOMAC pain subscale-were randomized to receive GS/ CS or the RP for 24 weeks. The primary efficacy endpoint was the absolute change in WOMAC pain subscale score. The secondary endpoints included the following: WOMAC total and subscale scores, overall assessment of the disease by the patient and the investigator, SF-12 score, OMERACT-OARSI response rate to the treatment, and rescue medication use.

Results: Mean reductions of WOMAC pain score were $-35.1(\mathrm{sd}=23.2) \mathrm{mm}$ in the GS/CS group and -36.5 ( $\mathrm{sd}=$ 24.9) $\mathrm{mm}$ in the RP group. The difference between the adjusted means of both treatments confirmed the noninferiority of GS/CS versus the RP. Improvement was observed in pain, stiffness, physical function and total WOMAC score, as well as in overall OA assessment by the patient and the investigator for both groups. No improvement was observed in SF-12. The rate of OMERACT-OARSI responders was $89.4 \%$ in GS/CS group and $87.9 \%$ in the RP group. Headache and changes in glucose tolerance were the most frequent treatment-related adverse events.
\end{abstract}

(Continued on next page)

\footnotetext{
* Correspondence: andrea.lomonte@cepic.com.br

${ }^{1}$ Centro Paulista de Investigação Clínica (CEPIC), Rua Moreira e Costa, 342 Ipiranga, São Paulo, SP 04266-010, Brazil

Full list of author information is available at the end of the article
}

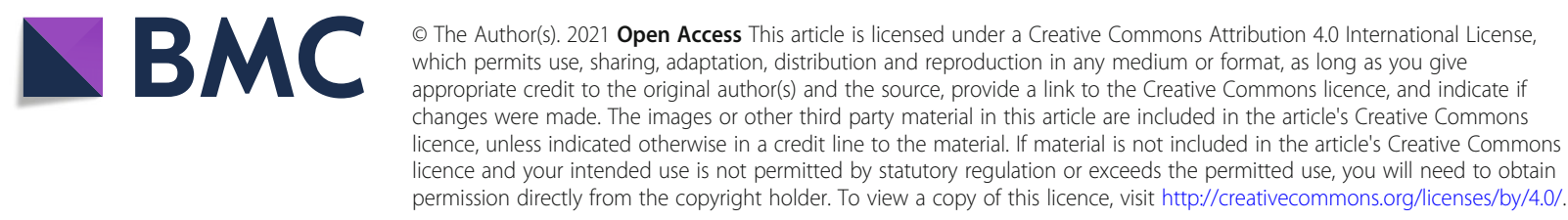


(Continued from previous page)

Conclusions: The new formulation of a fixed-dose combination of glucosamine sulfate and bovine chondroitin sulfate was non-inferior to the RP in symptomatic treatment of knee OA, with a high responder rate and good tolerability profile.

Trial registration: ClinicalTrials.gov; Registration number NCT02830919; Date of registration: July 13, 2016; First randomization date: December 05, 2016).

Keywords: Glucosamine, Chondroitin, Osteoarthritis, Knee, Pain

\section{Introduction}

Osteoarthritis (OA) is an important cause of morbidity and functional impairment [1]. An increase of $31.4 \%$ in disability-adjusted life-years (DALYs) was observed for musculoskeletal diseases, including OA, from 2007 to 2017 [2]. The functional impairment caused by this disease has a significant socioeconomic impact: a review of studies published between 2006 and 2016 addressing the economic impact of OA showed that the average per patient direct costs of the disease in the United States ranged from US\$ 1442 to US\$21,335 per year [3].

Symptomatic knee OA is a highly prevalent disease, affecting nearly 14 million people in the United States [4]. A continuous growth in disease incidence is expected, due to increased life expectancy and the prevalence of obesity, which is a known risk factor for OA [4, 5].

Therefore, it is important to investigate therapies which can promote symptomatic relief without risks of severe adverse events. The current treatment algorithm of the European Society for Clinical and Economic Aspects of Osteoporosis, Osteoarthritis and Musculoskeletal Diseases (ESCEO) proposes the early introduction of symptomatic slow-acting drugs for OA (SYSADOAs), among which glucosamine sulfate and chondroitin sulfate are included [6].

Glucosamine is an aminosaccharide which corresponds to the main component of the glycosaminoglycans that form the matrix of connective tissue. Glucosamine acts by increasing the synthesis of proteoglycans, and by inhibiting enzymes that degrade the cartilage, such as collagenase, phospholipase A2 and lysosomal enzymes [7, 8]. Furthermore, glucosamine inhibits several pro-inflammatory mediators, such as nitric oxide, cyclooxygenase-2 and metalloproteinases [9].

Chondroitin sulfate consists of repeated chains of sulfate glycosaminoglycans, which are important components of the extracellular matrix of connective tissue. Its main functions include: granting resistance and elasticity to articular cartilage, inhibiting the synthesis of inflammatory mediators and catabolic enzymes, stimulating the synthesis of cartilage matrix components, and reducing chondrocyte apoptosis [10, 11]. Chondroitin sulfate may have different origins and may be obtained from different animal species.
Currently, medicinal products which are extracted from avian, bovine, porcine, and marine (shark) sources are available worldwide. Randomized clinical trials with chondroitin sulfate from these different origins have already been conducted [10,12].

In Brazil, a product containing glucosamine sulfate and chondroitin sulfate of shark origin, Ártico ${ }^{\circledR}$ (Eurofarma Laboratórios S.A., São Paulo, S.P., Brazil), is commercially available. However, due to increasing scarcity of many shark species, replacing sharks with another animal species as a source of raw material for chondroitin production has become necessary. This led to the search for other source of chondroitin sulfate for this product.

The purpose of this study was to evaluate the efficacy and safety of a new formulation for Ártico ${ }^{\circledR}$ using a fixed-dose combination of glucosamine sulfate (1500 $\mathrm{mg}$ ) and chondroitin sulfate $(1200 \mathrm{mg})$ of bovine origin provided in sachets for the treatment of knee OA and establishing its non-inferiority compared to the reference product (RP), Condroflex ${ }^{\odot}$ (Zodiac Laboratórios S.A., São Paulo, S.P., Brazil). The choice of the comparator, which also contains chondroitin of bovine origin, was a requirement of the Brazilian food and drug regulatory agency (Agência Nacional de Vigilância Sanitária, ANVI SA) for this clinical trial.

\section{Patients and methods}

Study design. This phase III, multicenter, randomized, single-blind, non-inferiority, parallel-group, activecontrolled clinical trial was conducted from December 2016 to November 2018 at six Brazilian sites.

During the screening period, routine laboratory tests, knee $\mathrm{x}$-rays, and physical exams were performed, and clinical histories and information on ongoing medications were collected. Radiographs were read at each study site, to determine the Kellgren-Lawrence grade of knee OA. All pharmacological treatments for OA were discontinued, and only paracetamol $(500 \mathrm{mg}$ up to 4 times daily) was allowed for residual pain. A specific washout period between screening and randomization visits was defined for each non-steroidal antiinflammatory drug (NSAID) for patients undergoing such treatment. 
The randomization visit (RV) was performed up to 15 days after the screening visit (SV). Clinical visits were scheduled 1 week (visit 1 - V1), 6 weeks (visit 2 - V2), 12 weeks (visit 3 - V3), 18 weeks (visit 4 - V4), and 24 weeks (final visit - FV) after the RV. Efficacy evaluations were performed at visits V2, V3, and FV. Both treatments were administered throughout the study, with a maximum treatment duration of 171 days.

\section{Ethics, consent, and permissions}

The study was conducted under international and local ethical standards and regulations, in accordance with the principles of the Declaration of Helsinki. It was approved by the Research Ethics Committee (RECs) of each participating institution before its beginning, with the following RECs and their respective sites: Faculdade de Medicina do ABC/ Fundação do ABC (Centro Paulista de Investigação Clínica and Instituto de Pesquisa Clínica e Medicina Avançada), Comitê Permanente de Ética em Pesquisa com Seres Humanos - COPEP (Clínica Clinilive), Comitê de Ética em Pesquisa em Seres Humanos do Hospital de Clínicas da Universidade Federal do Paraná (Centro de Estudos em Terapias Inovadoras), Comitê de Ética em Pesquisa da Associação de Assistência à Criança Deficiente (Associação de Assistência à Criança Deficiente), and Comitê de Ética em Pesquisa do Hospital Alberto Rassi - CEPHGG (Centro Internacional de Pesquisa).

\section{Patients}

Eligible patients met the following criteria:

1. $\geq 40$ years old;

2. Diagnosed with knee OA as per the American College of Rheumatology (ACR) criteria;

3. Graded 2 or 3 by the Kellgren-Lawrence imaging classification;

4. Presented with pain in the target knee within 3 months prior to study screening;

5. Scored $\geq 40 \mathrm{~mm}$ in the visual analogue scale (VAS 0 to $100 \mathrm{~mm}$ ) for pain assessment (at the SV, and mean score $\geq 40 \mathrm{~mm}$ in the pain subscale of the Western Ontario and McMaster Universities (WOMAC) questionnaire at the randomization visit);

6. ACR functional status I to III.

All subjects gave written informed consent before inclusion in the study.

The main exclusion criteria included:

1. Diagnosis of other diseases of the knee;

2. Serious knee misalignment;
3. Serious trauma or surgery in the target knee within 6 months prior to enrollment,

4. Symptomatic OA of the ipsilateral hip;

5. Use of NSAIDs, dipyrone and opioid analgesics or narcotics from the SV, or washout period for these drugs shorter than defined by the protocol;

6. Use of oral, intravenous, or intramuscular corticosteroids within 30 days prior to the SV;

7. Intra-articular injection of corticosteroids and/or hyaluronic acid in the target knee within 6 months prior to the SV;

8. Use of diacerein, chloroquine, or soybean and avocado unsaponifiable extracts within the last 3 months; duloxetine hydrochloride over the last 30 days; glucosamine sulfate and/or chondroitin sulfate and strontium ranelate in the past 6 months;

9. Body mass index $(\mathrm{BMI}) \geq 40 \mathrm{~kg} / \mathrm{m} \mathrm{[2]}$;

10. Fasting blood glucose $>110 \mathrm{mg} / \mathrm{dL}$ or glycated hemoglobin $(\mathrm{HbA} 1 \mathrm{c})>6.5 \%$.

In case of bilateral knee OA, a target knee was defined as the knee with the most severe pain symptoms according to medical evaluation.

\section{Treatment and randomization}

Eligible patients were randomized at a 1:1 ratio to one of the following study groups: [1] a group treated with the new formulation of a fixed-dose combination of glucosamine sulfate $(1500 \mathrm{mg})$ and bovine chondroitin sulfate (1200 mg) (GS/CS group, Eurofarma Laboratórios S.A. São Paulo, S.P., Brazil) or [2] a group treated with the $\mathrm{RP}$ of glucosamine sulfate $(1500 \mathrm{mg})$ and bovine chondroitin sulfate $(1200 \mathrm{mg})$ (Condroflex ${ }^{\oplus}$, Zodiac Laboratórios S.A., São Paulo, S.P., Brazil). In both groups, the drug was supplied in sachets, and a daily dosage of one sachet was administered. Randomization was made through an interactive web response system (IWRV) integrated to the electronic case report form (eCRF), by which a code was informed to identify the product to be dispensed to each subject. Since the organoleptic properties (powder, color, and flavor) are different in both study treatments, the study was single-blinded, and only the patient and the study pharmacist were unblinded to the assigned treatment. The investigator and all other members of the study team were kept blind to the study treatment. Patients were instructed not to reveal the characteristic of the product in use to the investigator throughout the study. The sachet package (primary package) given to both groups had a similar characteristic, and identical labels were stuck to the sachets of both products to hide all available information and differences in the original packaging. The single-blind nature of the study was kept by using boxes (secondary package) with similar appearance and form for both study treatments. 


\section{Efficacy and safety evaluations}

The following efficacy evaluations were performed:

- Primary endpoint:

- Absolute change in pain subscale score on WOMAC questionnaire (normalized for 0 to 100 $\mathrm{mm}$ ) at week 24 versus baseline score.

- Secondary endpoints:

- Absolute change in pain, stiffness, and function subscale scores on WOMAC questionnaire (normalized for 0 to $100 \mathrm{~mm}$ ) throughout the treatment in relation to baseline score;

- Absolute change in overall assessment of the disease by the patient and investigator throughout the treatment, using the visual analogue scale (VAS) (0 to $100 \mathrm{~mm}$ ), in relation to baseline assessment;

- Absolute change in score of physical and mental components of Short Form-12 (SF-12) questionnaire at week 24 versus baseline score;

- Treatment response rate throughout the study, according to the Outcome Measures in Rheumatology Clinical Trials and Osteoarthritis Research Society International (OMERACTOARSI) criteria;

- Number of tablets of rescue medication administered during treatment.

The WOMAC questionnaire was administered by a professional duly trained for such a purpose in each study site, and patients were instructed to give answers only considering symptoms in the target knee within the previous $48 \mathrm{~h}$.

Rescue medication consisted of paracetamol (500 mg). Up to 4 tablets/day was allowed for no more than 5 consecutive days. Patients were instructed not to use paracetamol within $12 \mathrm{~h}$ before visits in which efficacy analyses were scheduled.

Safety evaluation outcomes included:

- Incidence and profile of adverse events (AEs);

- Frequency of discontinuations due to AEs and laboratory abnormalities.

\section{Statistical analysis}

Sample size calculations were based on the evaluation of a non-inferiority hypothesis of GS/CS compared to the reference product, established in terms of the primary efficacy variable. It was considered the one-sided means test for two independent samples (significance level= $2.5)$, the difference between the treatment means equal to zero, a standard deviation of $98 \mathrm{~mm}$, and a noninferiority margin of $35 \mathrm{~mm}$ for the pain subscale of the WOMAC score (ranging from 0 to $500 \mathrm{~mm}$, or equivalent to $7 \mathrm{~mm}$ in a normalized scale from 0 to 100 $\mathrm{mm}$ ). We determined that 250 patients (125 in each study group) would give $80 \%$ of power to demonstrate the non-inferiority of the investigational product compared to the reference product. The estimated rate of patient withdrawal from the per protocol population (PP) was 20\%, with randomization of 314 subjects planned.

In order to update the standard deviation sample size estimations, a blinded interim analysis was conducted after 214 patients completed the study. The estimated standard deviation value was $134.6 \mathrm{~mm}$ and the adjusted sample size was 468 patients. Considering a withdrawal rate from the PP population of $20 \%$, it was established that 586 patients would be enrolled in the study.

The efficacy evaluations were performed in the intention to treat (ITT) population and in the PP population. The ITT population was defined as all randomized study subjects that received at least one dose of the study drug and that had at least one primary assessment of efficacy. The PP population was composed of all subjects of the ITT population that completed the study, that had a drug adherence between 80 and $120 \%$ and that were compliant with all study requirements. The safety evaluations were conducted to all randomized study subjects that received at least one dose of the study drug.

A covariance analysis model was adjusted for assessment of the primary efficacy variable, with the treatment group as a fixed factor and the site and baseline WOMAC pain subscale score as covariates. The evaluation of noninferiority of GS/CS versus the reference product was conducted based on the two-sided confidence interval (95\%) for the difference between the means of absolute changes of the WOMAC pain subscale score between study groups, with the non-inferiority of GS/CS combination versus the reference product being stated if the upper limit of the confidence interval was lower than the noninferiority margin of $7 \mathrm{~mm}$.

For all secondary efficacy variables, a two-sided confidence interval (95\%) was established for the difference between the groups. Covariance models and analysis of variance models for repeated measures were adjusted for group comparisons.

Patient distribution according to OMERACT-OARSI treatment response criteria was evaluated through a generalized linear model for repeated measures, considering the binomial response, treatment, and week as factors, and treatment"week interaction, and site as covariates.

The mixed-effects Poisson regression model was used in the analysis of the number of tablets of rescue medication administered per week, pre- and post-treatment.

Safety analyses were performed through descriptive statistics and confidence intervals (95\%). 


\section{Results}

Demographics and baseline clinical characteristics

A total of 858 patients were screened for the study, 627 of which fulfilled the eligibility criteria and were randomized. A total of 314 patients were assigned to the GS/CS group and 313 patients were assigned to the RP group. All patients received the treatment to which they were randomized, except for a patient who was randomized to the GS/CS group but received the reference drug at V3. This patient was discontinued at V4. Among randomized patients, 489 (78\%) completed the study (251 (79.9\%) in the GS/ CS group and 238 (76\%) in the reference group). The most frequent reasons for early treatment

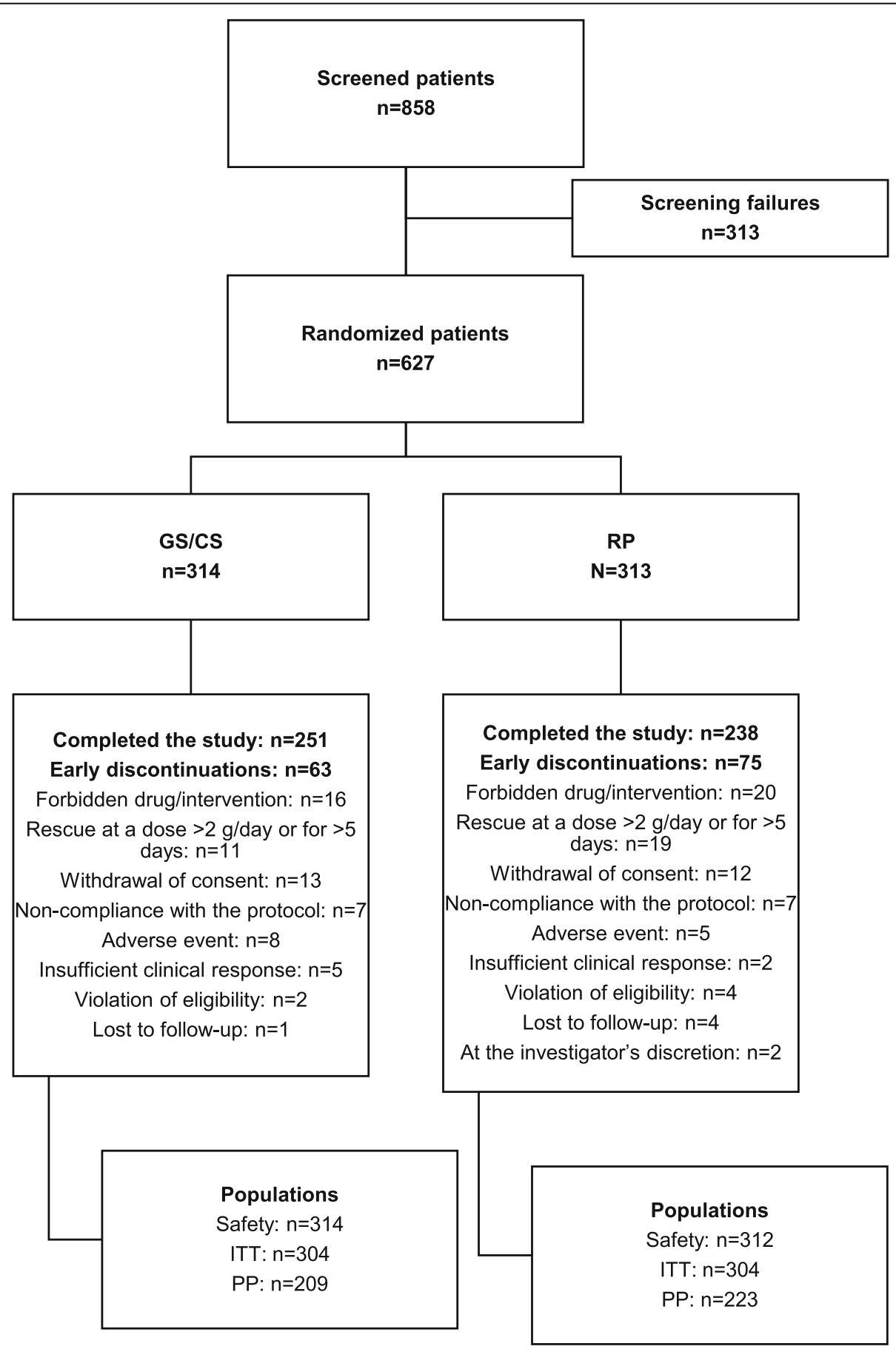

Fig 1 Disposition of study patients 
discontinuation were use of forbidden medications, inadequate use of rescue therapy, and withdrawal of consent. Figure 1 shows patients' disposition in both study groups and populations.

Demographics and baseline clinical characteristics of the studied population are presented in Table 1. Most patients were female and Caucasian, with a median BMI of $30.6 \mathrm{~kg} / \mathrm{m}^{2}$, indicating obesity grade I. Patients' age ranged from 40 to 86 years, predominantly over 60 (65.9\%). Mean OA duration was around 7 years in both groups. Most patients were Kellgren-Lawrence grade 2 on the target knee (67\% in both groups). The mean value (standard deviation, sd) of the WOMAC questionnaire pain subscale score was approximately $67.2(\mathrm{sd}=$ 13.4) $\mathrm{mm}$ for the studied population. Systemic arterial hypertension was the most frequent comorbidity in both groups. Demographics and clinical characteristics of the PP population were similar to the ITT population, and treatment groups were homogeneous for these characteristics.

Table 1 Baseline clinical and demographic characteristics in PP population

\begin{tabular}{|c|c|c|}
\hline Baseline characteristics & $\mathrm{GS} / \mathrm{CS}(N=209)$ & $\operatorname{RP}(N=223)$ \\
\hline Female, n (\%) & $184(88)$ & $193(86.6)$ \\
\hline Age, mean (sd), years & $62.8(8.9)$ & $63(8)$ \\
\hline Caucasian, n (\%) & $133(63.6)$ & $133(59.6)$ \\
\hline Osteoarthritis duration, mean (sd), years & $7.7(6.9)$ & $7.4(5.7)$ \\
\hline BMI, mean (sd), $\mathrm{kg} / \mathrm{m}^{2}$ & $30.4(4.7)$ & $30.7(4.4)$ \\
\hline \multicolumn{3}{|l|}{ Kellgren-Lawrence grading, $\mathrm{n}(\%)$} \\
\hline II & $146(69.9)$ & $151(67.7)$ \\
\hline III & $63(30.1)$ & $72(32.3)$ \\
\hline Overall assessment of OA by the patient, mean (sd), VAS $0-100 \mathrm{~mm}$ & $66.7(18.1)$ & $65(19.2)$ \\
\hline Overall assessment of OA by the physician, mean (sd), VAS $0-100 \mathrm{~mm}$ & $61.8(12.5)$ & $62.9(14.1)$ \\
\hline \multicolumn{3}{|l|}{ WOMAC, mean (sd), mm } \\
\hline Pain subscale & $66.3(13.2)$ & $68.1(13.5)$ \\
\hline Stiffness subscale & $64.9(21.1)$ & $65.4(20.9)$ \\
\hline Physical function subscale & $65.7(13.7)$ & $65.4(14.6)$ \\
\hline Total score & $196.9(39.9)$ & $198.9(41.7)$ \\
\hline \multicolumn{3}{|l|}{ SF-12, mean (sd) } \\
\hline Physical component & $34.9(7.4)$ & $35.7(7.5)$ \\
\hline Mental component & 49 (10.6) & $46.9(11.3)$ \\
\hline \multicolumn{3}{|l|}{ Comorbidities (reported by $\geq 5 \%$ of patients), $n$ (\%) } \\
\hline Back pain & $56(25.8)$ & $61(27.4)$ \\
\hline Musculoskeletal pain / Arthralgia / Pain in the extremities & $46(22)$ & $46(20.6)$ \\
\hline Osteoporosis/ Osteopenia & $34(16.3)$ & $30(13.5)$ \\
\hline Dyslipidemia / Hypercholesterolemia & $69(33)$ & $70(31.4)$ \\
\hline Impaired glucose tolerance & $33(15.8)$ & $40(17.9)$ \\
\hline Headache / Migraine & $60(28.7)$ & $77(34.5)$ \\
\hline Hypothyroidism & $40(19.1)$ & $39(17.5)$ \\
\hline Gastritis & $26(12.4)$ & $30(13.5)$ \\
\hline Gastroesophageal reflux disease & $9(4.3)$ & $14(6.3)$ \\
\hline Depression & $13(6.2)$ & $17(7.6)$ \\
\hline Insomnia & $11(5.3)$ & $15(6.7)$ \\
\hline Systemic arterial hypertension & $128(61.2)$ & $130(58.3)$ \\
\hline Lower limbs varices & $44(21.1)$ & $69(30.9)$ \\
\hline
\end{tabular}

$P<0,05$ between groups for all characteristics. BMl body mass index, $\mathrm{kg} / \mathrm{m}^{2}$ kilogram per square meter, GS/CS glucosamine sulfate/ chondroitin sulfate, $n$ (\%) number and percentage of patients in relation to the total number of patients in PP population, OA osteoarthritis, $P P$ per protocol, $R P$ reference product, sd standard deviation, SF-12 short-form 12 questionnaire, VAS visual analogue scale, WOMAC Western Ontario and McMaster Universities index 
The mean value of treatment adherence in the PP population was $97.1(\mathrm{sd}=4) \%$ in the GS/CS group and 96.1 ( $\mathrm{sd}=4.8) \%$ in the reference group, with no statistically significant difference between the groups.

\section{Efficacy Outcomes \\ Primary efficacy analysis}

The mean value of the pain subscale score at baseline was $66.3(\mathrm{sd}= \pm 13.2) \mathrm{mm}$ in GS/CS group and $68.1(\mathrm{sd}=$ 13.5) $\mathrm{mm}$ in the reference group. Mean reductions of the WOMAC pain subscale score on week 24 compared to baseline in the PP population was $-35.1 \quad(\mathrm{sd}=23.2)$ $\mathrm{mm}$ (a $53 \%$ reduction) in the GS/CS group and -36.5 $(\mathrm{sd}=24.9) \mathrm{mm}$ (a $53.7 \%$ reduction) in the reference group, with a between-treatments difference of $1.4 \mathrm{~mm}$ $(\mathrm{CI}=95 \%$ : $-3.2 \mathrm{~mm} ; 6 \mathrm{~mm})$. Adjusted estimates obtained from a covariance analysis model showed a reduction in pain score at the end of the study of $-30.9( \pm 2)$ $\mathrm{mm}$ in GS/CS group and $-31.8( \pm 2) \mathrm{mm}$ in the reference group, with a between-treatments difference of adjusted means of $0.9( \pm 2.1) \mathrm{mm}$ and respective CI (95\%) equal to $(-3.21 \mathrm{~mm} ; 4.99 \mathrm{~mm})$. In the ITT population, adjusted estimates showed a mean reduction of the WOMAC pain subscale of $-29.5(\mathrm{sd}=1.7) \mathrm{mm}$ in the GS/CS group and $-28.9(\mathrm{sd}=1,7) \mathrm{mm}$ in the RP group on week 24 compared to baseline, with a betweentreatments difference of -0.5 (CI 95\%: $-4.2 \mathrm{~mm} ; 3.1$ $\mathrm{mm})$. In both PP and ITT population, the upper limit of the confidence interval of the difference between the adjusted mean of both treatments for the pain subscale was lower than the non-inferiority margin of $7 \mathrm{~mm}$ established prior to the study, confirming the noninferiority of the new GS/CS fixed-dose combination versus the RP.

\section{Secondary efficacy analyses}

Table 2 shows the changes in the WOMAC score and Table 3 shows the results for the other secondary efficacy endpoints. No statistically significant difference between the groups was observed for secondary efficacy evaluations conducted in all timepoints throughout the study, both in PP and in ITT populations. These data support the non-inferiority of the new GS/CS formulation versus the reference product.

Improvements were observed in both treatment groups in pain, stiffness, physical function and total WOMAC score 6,12 , and 24 weeks after treatment initiation. A statistically significant improvement was also observed in the VAS for overall OA assessment, both by the patient and the investigator. These outcomes are represented in Fig. 2.

No statistically significant effects of treatment related to physical $(p=0.369)$ and mental $(p=0.089)$ components of the SF-12 questionnaire were observed 24 weeks after treatment initiation, with no difference between groups.

A progressive increase in the response rate to treatment according to OMERACT-OARSI criteria was

Table 2 Changes in the WOMAC score during the treatment in PP population ${ }^{\text {a }}$

\begin{tabular}{|c|c|c|c|c|}
\hline WOMAC & $\begin{array}{l}\text { GS/ CS } \\
(N=209)\end{array}$ & $\begin{array}{l}\mathrm{RP} \\
(\mathrm{N}=223)\end{array}$ & Difference between the treatments & $\mathrm{Cl}(95 \%)$ \\
\hline \multicolumn{5}{|c|}{ Absolute change in score of WOMAC "pain" subscale, mm, mean (se) } \\
\hline Week 6 & $-18.2(1.7)$ & $-20.2(1.72)$ & $1.98(2)$ & $(-1.95 ; 5.9)$ \\
\hline Week 12 & $-23.3(1.7)$ & $-24.7(1.7)$ & $1.3(2)$ & $(-2.6 ; 5.3)$ \\
\hline Week 24 & $-32.8(1.8)$ & $-33.3(1.7)$ & $0.54(2)$ & $(-3.5 ; 4.5)$ \\
\hline \multicolumn{5}{|c|}{ Absolute change in score of WOMAC "stiffness" subscale, mm, mean (se) } \\
\hline Week 6 & $-15.4(2)$ & $-17(2)$ & $1.6(2.3)$ & $(-3 ; 6.1)$ \\
\hline Week 12 & $-19.1(2)$ & $-22.5(2)$ & $3.4(2.3)$ & $(-1.1 ; 8)$ \\
\hline Week 24 & $-28.6(2)$ & $-30.1(2)$ & $1.4(2.4)$ & $(-3.2 ; 6.1)$ \\
\hline \multicolumn{5}{|c|}{ Absolute change in score of WOMAC "function" subscale, mm, mean (se) } \\
\hline Week 6 & $-14.2(1.7)$ & $-15.1(1.7)$ & $0.9(2)$ & $(-2.94 ; 4.78)$ \\
\hline Week 12 & $-19.6(1.7)$ & $-21.4(1.7)$ & $1.8(2)$ & $(-2.1 ; 5.7)$ \\
\hline Week 24 & $-28.9(1.8)$ & $-29.5(1.7)$ & $0.6(2)$ & $(-3.3 ; 4.5)$ \\
\hline \multicolumn{5}{|c|}{ Absolute change in WOMAC total score, $\mathrm{mm}$, mean (se) } \\
\hline Week 6 & $-48.1(5.1)$ & $-52.83(5)$ & $4.8(5.8)$ & $(-6.6 ; 16.1)$ \\
\hline Week 12 & $-62.3(5.1)$ & $-69.1(5)$ & $6.9(5.8)$ & $(-4.6 ; 18.3)$ \\
\hline Week 24 & $-90.6(5.1)$ & $-93.4(5.1)$ & $2.9(5.9)$ & $(-8.7 ; 14.4)$ \\
\hline
\end{tabular}

${ }^{a}$ Estimates of the mixed model for repeated measures adjusted per baseline score and site. $\mathrm{Cl}$ (95\%) two-sided confidence interval for change mean, with confidence coefficient of $95 \%, G S / C S$ glucosamine sulfate/ chondroitin sulfate, PP per protocol, RP Reference Product, se standard estimate, WOMAC Western Ontario and McMaster Universities questionnaire (score normalized at the scale from 0 to $100 \mathrm{~mm}$ ) 
Table 3 Secondary efficacy analyses during the treatment in PP population ${ }^{\text {a }}$

\begin{tabular}{|c|c|c|c|c|}
\hline Efficacy endpoint & $\begin{array}{l}\text { GS/ CS } \\
(N=209)\end{array}$ & $\begin{array}{l}\mathrm{RP} \\
(\mathrm{N}=223)\end{array}$ & Difference between the treatments ${ }^{b}$ & $\mathrm{Cl}(95 \%)$ \\
\hline \multicolumn{5}{|c|}{ Absolute change in overall OA assessment by the patient (VAS), mm, mean (se) } \\
\hline Week 6 & $-20.2(1.9)$ & $-18.8(1.9)$ & $-1.37(2.2)$ & $(-5.72 ; 3)$ \\
\hline Week 12 & $-24.4(1.9)$ & $-24.5(1.9)$ & $0.2(2.2)$ & $(-4.2 ; 4.5)$ \\
\hline Week 24 & $-35.5(1.9)$ & $-32.6(1.9)$ & $-2.9(2.3)$ & $(-7.3 ; 1.5)$ \\
\hline \multicolumn{5}{|c|}{ Absolute change in overall OA assessment by the physician (VAS), mm, mean (se) } \\
\hline Week 6 & $-20(1.5)$ & $-21.6(1.4)$ & $1.6(1.7)$ & $(-1.7 ; 5)$ \\
\hline Week 12 & $-27.1(1.5)$ & $-28.5(1.5)$ & $1.4(1.7)$ & $(-1.9 ; 4.8)$ \\
\hline Week 24 & $-37.6(1.5)$ & $-36.7(1.5)$ & $-0.9(1.7)$ & $(-4.3 ; 2.5)$ \\
\hline \multicolumn{5}{|c|}{ Absolute change in SF-12 physical component, points, mean (se) } \\
\hline Week 24 & $5(0.7)$ & $5.7(0.7)$ & $-0.7(0.7)$ & $(-2.1 ; 0.8)$ \\
\hline \multicolumn{5}{|c|}{ Absolute change in SF-12 mental component, points, mean (se) } \\
\hline Week 24 & $2.7(0.9)$ & $1.12(0.9)$ & $1.6(0.9)$ & $(-0.2 ; 3.4)$ \\
\hline \multicolumn{5}{|c|}{ Treatment response rate by OMERACT-OARSI criteria, $\mathrm{n}(\%)$} \\
\hline Week 6 & $130(62.5)$ & $137(61.4)$ & 1.1 & $(-8.1 ; 10.2)$ \\
\hline Week 12 & $143(69.8)$ & $155(69.8)$ & -0.1 & $(-8.8 ; 8.7)$ \\
\hline Week 24 & $166(83.4)$ & $172(80.4)$ & 3 & $(-4.4 ; 10.5)$ \\
\hline \multicolumn{5}{|c|}{ Number of tablets of rescue medication administered per week, mean (se) } \\
\hline SV to RV & $3.8(4.8)$ & $3.7(4.7)$ & & \\
\hline RV to V2 & $1.4(2.2)$ & $1.3(2)$ & & \\
\hline V2 to V3 & $0.9(1.8)$ & $0.9(1.7)$ & & \\
\hline V3 to V4 & $0.8(1.7)$ & $0.8(1.7)$ & & \\
\hline V4 to FV & 0.7 (1.6) & $0.8(1.5)$ & & \\
\hline
\end{tabular}

${ }^{a}$ Estimates of the mixed model for repeated measures adjusted per baseline score and site. ${ }^{b}$ Difference between the treatments evaluated by the mean (se) for VAS and SF-12 variables, and as percentage of responders to the treatment for OMERACT-OARSI criteria. $\mathrm{Cl}$ (95\%) two-sided confidence interval for change mean, with confidence coefficient of $95 \%, G S / C S$ glucosamine sulfate/ chondroitin sulfate, OA osteoarthritis; se: standard estimate, OMERACT-OARSI Outcome Measures in Rheumatology Clinical Trials and Osteoarthritis Research Society International, PP per protocol, RP reference product, SF-12 Short Form 12 questionnaire, VAS visual analogue scale

observed throughout the study (Table 3). The overall response rate was $89.4 \%$ in the GS/CS group and $87.9 \%$ in the reference group, with a between-groups difference of 1.5 (CI 95\%: - 4.5\%; 7.5\%).

The median number of tablets of rescue medication used for pain in the knees during the total treatment period was 12 tablets in the GS/CS group and 13 tablets in the reference group. Table 2 shows the number of tablets of rescue treatment used at each study visit.

\section{Safety}

A total of 1076 AEs were reported during the study, of which 504 occurred in the GS/CS group and 572 in the reference group (most of mild intensity). The number of AEs considered related to the study treatment were 116 (23\%) in the GS/CS group and 160 (28\%) in the reference group.

The most frequent treatment-related $\mathrm{AE}$ was headache, reported by $12.7 \%$ of the patients in the GS/CS group and $14.4 \%$ of the patients in the reference group, followed by impaired glucose tolerance, reported by $2.9 \%$ of patients in the GS/CS group and 5.5\% of patients in the reference group. A summary of the AEs with incidence $\geq 5 \%$ in the safety population is described in Table 4.

Five serious adverse events (SAEs) were reported by 3 patients from the GS/CS group (intestinal obstruction and abdominal hernia repair; nephrolithiasis and urinary tract infection; and amyotrophic lateral sclerosis), and 2 SAEs were reported by 2 patients in the reference group (road traffic accident and cholecystitis); none of the reported SAEs were assessed as related to the study treatment. No deaths occurred during the study.

\section{Discussion}

Both formulations of a fixed-dose combination of glucosamine sulfate and bovine chondroitin sulfate provided in sachets provided clinically relevant improvement of pain and physical function in patients with primary OA of the knee, establishing proof of non-inferiority between the two products. An improvement in overall OA assessment was reported both by patients and investigators, and a progressive increase was observed in the rate of treatment responders according to OMERACT-OARSI criteria 


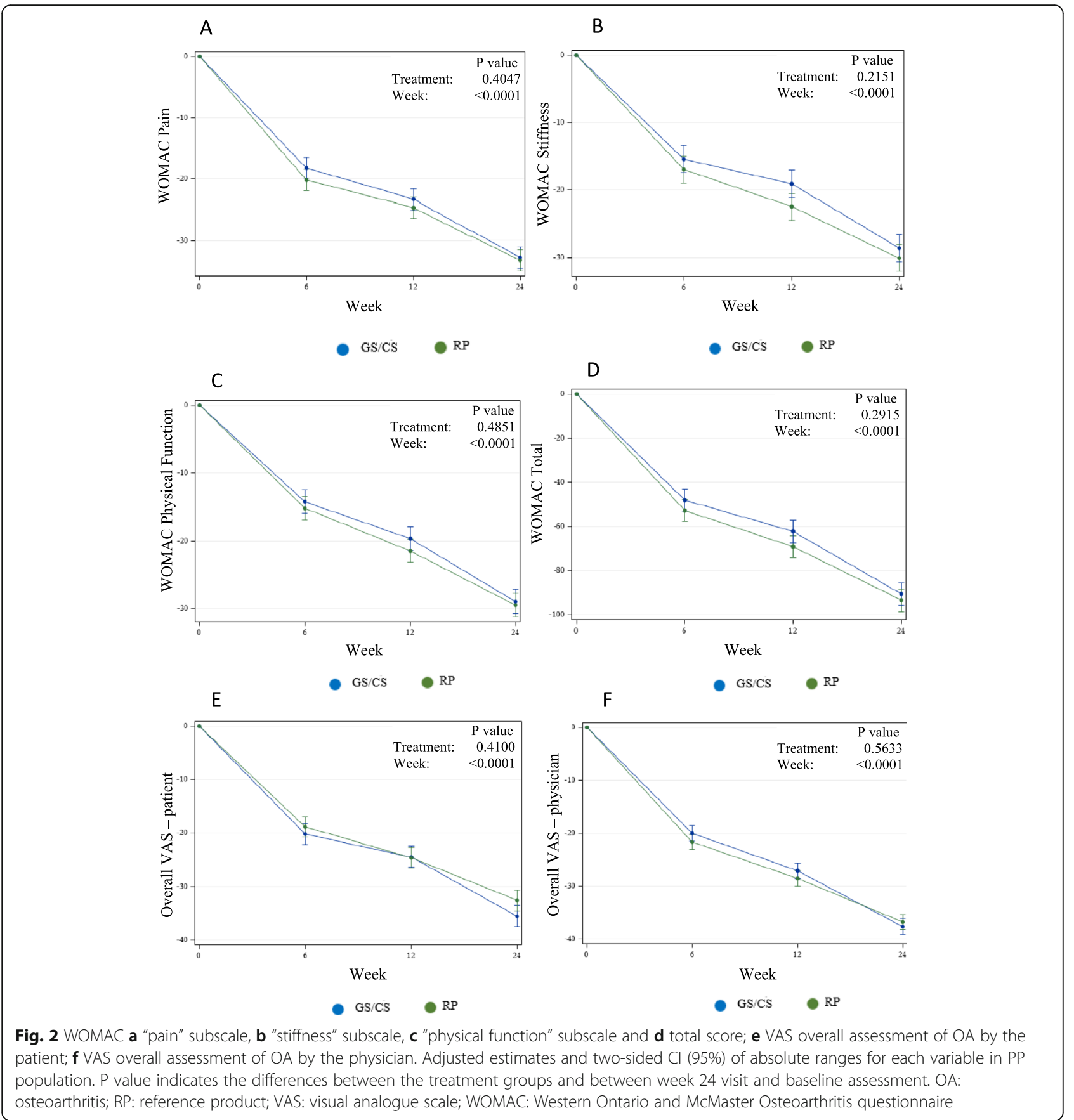

throughout the study, with over $80 \%$ of responders in each study group at the end of the 6-month treatment. On the other hand, no significant improvement in quality of life was observed in either group, as assessed by the SF-12 questionnaire.

The large number $(>600)$ of randomized patients is one of the strengths of this study. The study was conducted in several research sites, with evaluations performed during 24 weeks of treatment. Different endpoints were used, including a WOMAC questionnaire, VAS for overall disease assessment by the patient and the investigator, an SF-12 questionnaire, and treatment response rate evaluation as per OMERACT-OARSI criteria. The choice of comparator was a requirement of the Brazilian food and drug regulatory agency (Agência Nacional de Vigilância Sanitária, ANVISA), since the chondroitin sulfate substrate of the reference product is of bovine origin. The blinding strategy of the study treatments enabled keeping the singleblind nature of the study, despite drugs having different organoleptic characteristics. 
Table 4 Adverse events observed in the safety population

\begin{tabular}{|c|c|c|}
\hline Adverse events & $\mathrm{GS} / \mathrm{CS}(N=314)$ & $\mathrm{RP}(N=312)$ \\
\hline Patients reporting at least one $A E, n(\%)$ & $195(62.1)$ & $202(64.7)$ \\
\hline Total AEs reported, $\mathbf{n}$ & 504 & 572 \\
\hline Incidence of AEs considered related to the treatment, $\mathrm{n}(\%)$ & $67(21.3)$ & $85(27.2)$ \\
\hline Incidence of serious AEs, n (\%) & $3(0.96)$ & $2(0.6)$ \\
\hline Total of serious AEs, $n$ & 5 & 2 \\
\hline Incidence of AEs leading to treatment discontinuation, $n(\%)$ & $9(2.9)$ & $8(2.6)$ \\
\hline \multicolumn{3}{|l|}{ AEs with incidence $\geq \mathbf{5} \%$} \\
\hline Arthralgia, n (\%) & $15(4.8)$ & $19(6.1)$ \\
\hline Myalgia, n (\%) & $10(3.2)$ & $18(5.8)$ \\
\hline Back pain, $\mathrm{n}(\%)$ & $30(9.6)$ & $27(8.7)$ \\
\hline Pain in the extremity, $\mathrm{n}(\%)$ & $20(6.4)$ & $23(7.4)$ \\
\hline Impaired glucose tolerance, $\mathrm{n}(\%)$ & $12(3.8)$ & $20(6.4)$ \\
\hline Headache, n (\%) & $45(14.3)$ & $49(15.7)$ \\
\hline Upper respiratory tract infection, $n(\%)$ & $24(7.6)$ & $21(6.7)$ \\
\hline Nasopharyngitis, n (\%) & $13(4.1)$ & $19(6.1)$ \\
\hline Flu, n (\%) & $13(4.1)$ & $21(6.7)$ \\
\hline
\end{tabular}

$P<0.05$ between groups for all descriptions. AE(s): adverse event(s); GS/CS: glucosamine sulfate/ chondroitin sulfate; $n$ (\%): number and percentage of patients with at least one AE reported in relation to the total number of patients in the safety population; RP: reference product

The need for replacing the raw material for chondroitin manufacturing has led to the development of a new formulation and, therefore, is the initiative for this clinical trial. A fixed-dose combination of glucosamine sulfate and chondroitin sulfate obtained from shark cartilage (Ártico ${ }^{\circ}$, Eurofarma Laboratórios S.A., São Paulo, S.P., Brazil), is currently marketed in Brazil as a prescription product approved for medical use by ANVI SA, based on the demonstration of its efficacy and safety in previous clinical trials $[13,14]$. However, due to the need to protect increasingly endangered shark species whose populations have exponentially decreased over the last five decades, with no signs of a satisfactory recovery $[15,16]$, a new source of raw material for chondroitin has become necessary. The option of using bovine cartilage as a substrate for the new formulation was based on the wide availability of this raw material in the Brazilian territory, as well as on evidence of bovine chondroitin efficacy available in the medical literature.

Our findings support the efficacy and safety of the glucosamine sulfate and chondroitin sulfate combination. However, there is still much discussion in the scientific literature about the role of this combination in knee OA, due to controversial results from previous clinical trials. In a randomized, double-blind trial conducted in Spain, the glucosamine sulfate and chondroitin sulfate combination was not observed to be superior to a placebo during a 6-month treatment trial [17].

On the other hand, our results are similar to those from the MOVES study, in which the efficacy of the glucosamine hydrochloride and chondroitin sulfate combination was compared to celecoxib. Despite the differences in the methodologies between the studies, the high OMERACTOARSI response rate (79\% both for the glucosamine/chondroitin sulfate combination and for celecoxib) observed in the MOVES study was similar to the response rate found in our study [18]. The improvement in pain and physical function by the WOMAC questionnaire during 6 months of follow-up was also observed in both studies.

The safety profile of the new formulation was similar to the comparator drug. Headaches and changes in glucose tolerance were the most frequent treatment-related AEs. Different results regarding the effect of glucosamine on glucose metabolism are found in the literature [19]. No SAEs related to the study treatment were reported during the study. This data is supported by a systematic review and meta-analysis about safety of symptomatic slow-acting drugs for OA, which did not show any increase in the risk of SAEs or severe AEs compared to placebo [20].

One factor that could impact our study results was the use of paracetamol as a rescue therapy for OA residual pain. However, the use of the rescue therapy was low in both groups, and it would not be ethical to forbid the use of a pain relief medication during the study. Aiming to reduce the influence of the pain relief medication in questionnaire responses, its use was forbidden within 12 $\mathrm{h}$ prior to efficacy evaluations performed in the study. The Kellgren-Lawrence grade of knee OA was evaluated by a physician at each study site. The lack of a central 
reading system of the radiographs could introduce greater variability in the imaging interpretation and was another limitation. Another point to be mentioned is the proportion of over $60 \%$ of Caucasian people in this Brazilian study. According to the Brazilian Institute of Geography and Statistics (IBGE, Instituto Brasileiro de Geografia e Estatística), the self-reported race is white for about $40 \%$ of the Brazilian population [21], but we have seen more than $60 \%$ of white people in our sample. This could be explained by a larger number of patients who came from centers in São Paulo and Paraná, where there is a higher proportion of whites compared to other regions of the country. Finally, the high drop-out rate of over $20 \%$ is also a limitation of the present study, but a per protocol analysis did not show group differences.

\section{Conclusion}

In conclusion, this clinical study showed that the new formulation of a fixed-dose combination of glucosamine sulfate and chondroitin sulfate of bovine origin is not inferior to the reference product. The new combination showed a good safety profile in this large population studied. New controlled clinical studies with a large number of patients and evaluating treatment response rate with the combination of glucosamine sulfate and chondroitin sulfate are warranted.

\section{Acknowledgements}

The authors thank the trial subjects and the study team from each one of the sites involved in the clinical trial.

\section{Authors' contributions}

Dr. Andrea B. V. Lomonte contributed in the clinical trial conception, design, data acquisition, data analysis and interpretation, article writing. Dr. Emerson Gimenez, Dr. Antônio C. da Silva, Dr. Sebastião C. Radominski, Dr. Morton A. Scheinberg, Dr. Antônio C. Ximenes and Dr. Cristiano A. F. Zerbini contributed to data acquistion, study conduction, and article review. The authors read and approved the final manuscript.

\section{Funding}

Eurofarma Laboratórios S.A. funded this study and participated in the study design; study research; collection, analysis and interpretation of data; and writing, review, and approval of this article. All authors had access to the data and participated in the development, review, and approval of this article and in the decision to submit it for publication.

\section{Availability of data and materials}

The data that supports the findings of this study are available on request from the corresponding author [A.B.V.L.]. The data are not publicly available due to the privacy of data from research participants.

\section{Ethics approval and consent to participate}

The study was conducted following international and local ethical standards and regulations, and was approved by the Independent Ethics Committee from each participating institution before its beginning. The informed consent was obtained from all study participants before their inclusion in the clinical trial.

\section{Consent for publication}

Not applicable.

\section{Competing interests}

Dr. Andrea B. V. Lomonte was a medical-scientific advisor and was paid by Eurofarma Laboratórios S.A. to write the study protocol and the scientific article. Dr. Emerson Gimenez, Dr. Antônio Carlos da Silva, Dr. Sebastião Cezar Radominski, Dr. Morton Aaron Scheinberg, Dr. Antônio Carlos Ximenes, and Dr. Cristiano Augusto de Freitas Zerbini were investigators in that study and were paid by Eurofarma Laboratórios S.A. to conduct the clinical trial.

\section{Author details}

${ }^{1}$ Centro Paulista de Investigação Clínica (CEPIC), Rua Moreira e Costa, 342 Ipiranga, São Paulo, SP 04266-010, Brazil. nstituto de Pesquisa Clínica e Medicina Avançada (IMA Brasil), São Paulo, Brazil. ${ }^{3}$ Clínica Clinilive, Maringá, Brazil. ${ }^{4}$ Centro de Estudos em Terapias Inovadoras (CETI), Curitiba, Brazil.

${ }^{5}$ Associação de Assistência à Criança Deficiente (AACD), São Paulo, Brazil.

${ }^{6}$ Centro Internacional de Pesquisa, Goiânia, Brazil.

Received: 21 September 2020 Accepted: 4 January 2021

Published online: 19 January 2021

\section{References}

1. Vina ER, Kwoh CK. Epidemiology of osteoarthritis: literature update. Curr Opin Rheumatol. 2018;30(2):160-7.

2. GBD 2017 DALYs and HALE collaborators. Global, regional, and national disability-adjusted life-years (DALYs) for 359 diseases and injuries and healthy life expectancy (HALE) for 195 countries and territories, 1990-2017: a systematic analysis for the Global Burden of Disease Study 2017. Lancet. 2018;392:1859-922.

3. Xie F, Kovic B, Jin X, He X, Wang M, Silvestre C. Economic and humanistic burden of osteoarthritis: a systematic review of large sample studies. Pharmacoeconomics. 2016;34(11):1087-100.

4. Deshpande BR, Katz JN, Solomon DH, et al. Number of persons with symptomatic knee osteoarthritis in the US: impact of race and ethnicity, age, sex, and obesity. Arthritis Care Res (Hoboken). 2016;68(12):1743-50.

5. Bijlsma JW, Berenbaum F, Lafeber FP. Osteoarthritis: an update with relevance for clinical practice. Lancet. 2011;377(9783):2115-26.

6. Bruyère $\mathrm{O}$, Honvo $\mathrm{G}$, Veronese $\mathrm{N}$, et al. An updated algorithm recommendation for the management of knee osteoarthritis from the European Society for Clinical and Economic Aspects of osteoporosis, osteoarthritis and musculoskeletal diseases (ESCEO). Semin Arthritis Rheum. 2019;49(3):337-50

7. Towheed TE, Anastassiades T. Glucosamine therapy for osteoarthritis: an update. J Rheumatol. 2007;34(9):1787-90.

8. Piperno M, Reboul P, Hellio Le Graverand MP, Peschard MJ, et al. Glucosamine sulfate modulates dysregulated activities of human osteoarthritic chondrocytes in vitro. Osteoarthr Cartil. 2000;8(3):207-12.

9. Aghazadeh-Habashi A, Jamali F. The glucosamine controversy: a pharmacokinetic issue. J Pharm Sci. 2011;14(2):264-73.

10. Henrotin Y, Mathy M, Sanchez C, Lambert C. Chondroitin sulfate in the treatment of osteoarthritis: from in vitro studies to clinical recommendations. Ther Adv Musculoskelet Dis. 2010;2(6):335-48.

11. Hardingham T. Chondroitin sulfate and joint disease. Osteoarthritis Cartilage. 1998;6(Suppl A):3-5.

12. Fardellone P, Zaim M, Saurel AS, Maheu E. Comparative efficacy and safety study of two chondroitin sulfate preparations from different origin (avian and bovine) in symptomatic osteoarthritis of the knee. Open Rheumatol J. 2013;7:1-12

13. Brandão GC, Korukian M, Brandão DC, Mainine S, Souza Júnior AP. Association of glucosamine sulfate and chondroitin sulfate for patients with osteoarthritis of the knee. Rev Bras Med. 2009;66(11):405-8.

14. Lomonte ABV, Mendonça JA, de Castro BG, Castro ML. Multicenter, randomized, double-blind clinical trial to evaluate efficacy and safety of combined glucosamine sulfate and chondroitin sulfate capsules for treating knee osteoarthritis. Adv Rheumatol. 2018;58(1):41.

15. Roff G, Brown CJ, Priest MA, Mumby PJ. Decline of coastal apex shark populations over the past half century. Commun Biol. 2018;1:223.

16. Ferretti F, Curnick D, Liu K, Romanov EV, Block BA. Shark baselines and the conservation role of remote coral reef ecosystems. Science Advances. 2018; 4(3):eaaq0333. https://doi.org/10.1126/sciadv.aaq0333.

17. Roman-Blas JA, Castañeda S, Sánchez-Pernaute O, Largo R, HerreroBeaumont G. CS/GS combined therapy study group. Combined treatment with chondroitin sulfate and glucosamine sulfate shows no superiority over 
placebo for reduction of joint pain and functional impairment in patients with knee osteoarthritis: a six-month multicenter, randomized, double-blind, placebo-controlled clinical trial. Arthritis Rheumatol. 2017;69(1):77-85.

18. Hochberg MC, Martel-Pelletier J, Monfort J, et al. Combined chondroitin sulfate and glucosamine for painful knee osteoarthritis: a multicentre, randomised, double-blind, non-inferiority trial versus celecoxib. Ann Rheum Dis. 2016;75(1):37-44

19. Dostrovsky NR, Towheed TE, Hudson RW, Anastassiades TP. The effect of glucosamine on glucose metabolism in humans: a systematic review of the literature. Osteoarthr Cartil. 2011;19(4):375-80.

20. Honvo G, Reginster JY, Rabenda V, et al. Safety of symptomatic slow-acting drugs for osteoarthritis: outcomes of a systematic review and meta-analysis. Drugs Aging. 2019;36(Suppl 1):65-99.

21. IBGE. Pesquisa Nacional por Amostra de Domicílios Contínua Trimestral 2017-2020. http://www.sidra.ibge.gov.br/tabela/6403\#resultado. Accessed 22 Nov 2020.

\section{Publisher's Note}

Springer Nature remains neutral with regard to jurisdictional claims in published maps and institutional affiliations.

Ready to submit your research? Choose BMC and benefit from:

- fast, convenient online submission

- thorough peer review by experienced researchers in your field

- rapid publication on acceptance

- support for research data, including large and complex data types

- gold Open Access which fosters wider collaboration and increased citations

- maximum visibility for your research: over $100 \mathrm{M}$ website views per year

At BMC, research is always in progress.

Learn more biomedcentral.com/submissions 